\title{
Dysregulated NMDA-Receptor Signaling Inhibits Long-Term Depression in a Mouse Model of Fragile X Syndrome
}

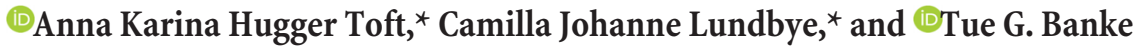 \\ Institute of Biomedicine, Physiology, Aarhus University, 8000 Aarhus, Denmark
}

Fragile X syndrome (FXS) is a neurodevelopmental disease. It is one of the leading monogenic causes of intellectual disability among boys with most also displaying autism spectrum disorder traits. Here we investigated the role of NMDA receptors on mGluR-dependent long-term depression (mGluR-LTD), a key biomarker in the disease, at four different developmental stages. First, we applied the mGluR agonist 3,5-dihydroxyphenylglycine in the absence or presence of the NMDAR blocker, APV, hereby unmasking the NMDAR component in this process. As expected, in the presence of APV, we found more LTD in the mouse KO than in WT. This, however, was only observed in the p30 - 60 age group. At all other age groups tested, mGluR-LTD was almost identical between K0 and WT. Interestingly, at p60, in the absence of APV, no or very little LTD was found in KO that was completely restored by application of APV. This suggests that the underlying cause of the enhanced mGluR-LTD in KO (at p30) is caused by dysregulated NMDAR signaling. To investigate this further, we next used NMDAR-subunit-specific antagonists. Inhibition of GluN2B, but not GluN2A, blocked mGluR-LTD only in WT. This was in contrast in the KO where blocking GluN2B rescued mGluR-LTD, suggesting GluN2B-containing NMDARs in the KO are hyperactive. Thus, these findings suggest strong involvement of GluN2B-containing-NMDARs in the pathophysiology of FXS and highlight a potential path for treatment for the disease.

Key words: autism; fragile X; GluN2B; long-term depression; mGluR; NMDA receptor antagonists

Significance Statement

There is currently no cure for fragile X, although medications targeting specific FXS symptoms do exist. The FXS animal model, the Fmr1 knock-out mouse, has demonstrated an increased mGluR5-mediated long-term depression (LTD) leading to several clinical trials of mGluR5 inhibitors/modulators, yet all have failed. In addition, surprisingly little information exists about the possible role of other ion channels/receptors, including NMDA receptors (NMDAR), in mGluR-LTD. Here we focus on NMDARs and their regulation of mGluR-mediated LTD at different developmental stages using several different NMDAR blockers/antagonists. Our findings suggest dysregulated NMDARs in the pathophysiology of FXS leading to altered mGluR-mediated LTD. Together, these data will help to develop new drug candidates that could lead to reversal of the FXS phenotype.

\section{Introduction}

Fragile X syndrome (FXS) is one of the leading monogenic causes of intellectual disability (Bagni and Oostra, 2013). The syndrome is most often caused by CGG trinucleotide repeat expansion in

Received Aug. 12, 2015; revised Aug. 2, 2016; accepted Aug. 5, 2016.

Author contributions: A.K.H.T. and T.G.B. designed research; A.K.H.T., C.J.L., and T.G.B. performed research;

A.K.H.T., C.J.L., and T.G.B. analyzed data; A.K.H.T. and T.G.B. wrote the paper.

${ }^{*}$ A.K.H.T. and C.J.L. contributed equally to this paper.

This work was supported by the Lundbeck Foundation, Denmark and Danish Council for Independent Research DFF-4004-00188. We thank Drs. Stephen Traynelis (Emory University) and Kasper Hansen (Montana University) for comments and experimental suggestions; and Dr. David Wyllie (Edinburgh University) for critically reading and commenting an earlier version of the manuscript.

The authors declare no competing financial interests.

Correspondence should be addressed to Dr. Tue G. Banke, Institute of Biomedicine, Physiology, Aarhus University, 8000 Aarhus, Denmark. E-mail: tbanke@biomed.au.dk.

DOI:10.1523/JNEUROSCI.3038-15.2016

Copyright $\odot 2016$ the authors $\quad 0270-6474 / 16 / 369817-11 \$ 15.00 / 0$ the fragile $\mathrm{X}$ mental retardation 1 (Fmr1) gene, resulting in abnormal DNA hypermethylation of both the CGG repeats and the regulatory $\mathrm{CpG}$ islands upstream of Fmr1. This leads to transcriptional silencing of its encoded protein, fragile X mental retardation protein (FMRP) (Penagarikano et al., 2007), which leads to severe symptoms, including intellectual disability, hyperactivity, facial dysmorphic features, hyperactivity, attention deficits, and autistic-like behavior (Pimentel, 1999; Bagni and Oostra, 2013). Currently, there is no effective treatment for patients with FXS.

FMRP is expressed throughout the CNS, with expression levels being particularly high at the dendritic spines, cytoplasm, and ribosomes bound to the endoplasmic reticulum (Pimentel, 1999; Bagni and Oostra, 2013). FMRP is mostly known as a repressor of specific mRNA translation and protein synthesis within the synapse throughout many phases of translational regulation but is also involved in trafficking of mRNA from the nucleus to the 
cytoplasm and distal postsynaptic sites (Zalfa et al., 2006; Penagarikano et al., 2007). In addition, using the mouse model of FXS (the Fmr1 knock-out mouse), FMRP seems to play important roles in synaptic plasticity. Thus, in conjunction with the characterization of a deficit in $N$-methyl-D-aspartate receptor (NMDAR)-dependent LTP and behavior (Zhao et al., 2005; Meredith et al., 2007; Hu et al., 2008; Shang et al., 2009; Lim et al., 2014; Martin et al., 2016), an increase in Group 1 metabotropic glutamate receptor (mGluR)-dependent LTD has been established in the hippocampal area CA1 (Huber et al., 2002; Michalon et al., 2012). The LTD type of plasticity formed the basis for the mGluR theory of FXS, which hypothesizes that the psychiatric and neurological aspects of FXS are a consequence of exaggerated responses to Group 1 mGluR activation (Bear et al., 2004).

FMRP regulates a number of synaptic proteins in the NMDAR/ mGluR5-Ras-PI3K/PKB (or Akt) signaling interactome (for review, see Darnell and Klann, 2013). Furthermore, FMRP has been found to associate with the mRNA of NMDAR subunit GluN1, GluN2A, and GluN2B (Schütt et al., 2009; Edbauer et al., 2010), which could indicate that NMDARs are involved in the pathophysiology of FXS. In support of this, differences in subunit levels have been found throughout different brain regions of the Fmr1 KO mice, including an increase of GluN1 and GluN2B in the hippocampus (Schütt et al., 2009).

To better understand the function of NMDARs in FXS, we examined their role on synaptic plasticity throughout postnatal development in wild-type (WT) mice and in mice lacking FMRP. We performed electrophysiological recordings measuring field potentials in the CA1 area of the hippocampus in the Fmrl knock-out (KO) mouse model in four different age groups (postnatal [p] p15p21, p30-p40, p60-p80, $p>120$ ). First, we induced mGluR-LTD in the presence or absence of the broad-spectrum NMDAR antagonists, APV, thereby unmasking the effect NMDARs have on mGluRdependent LTD. Together, we found that, throughout development in the WT mouse, 3,5-dihydroxyphenylglycine (DHPG)-induced LTD is under strong NMDAR regulation. Importantly, this magnitude of mGluR-LTD, however, is strongly dependent upon developmental stage of the animal: at the early juvenile stage (p15-p21), NMDARs modulated mGluR-LTD slightly negative; p 30 -p60, NMDAR modulated mGluR-LTD positively, and then finally at the adult stage $(p>120)$, NMDAR again modulated mGluR-LTD negatively. This was in sharp contrast to the KO mouse where, throughout development to adulthood, NMDAR modulation of mGluR-LTD was dramatically dysregulated. Furthermore, using NMDAR subunit-specific inhibitors, we have found that especially GluN2B is important in mGluR-LTD. Our data support a model where blockage of GluN2B in WT leads to strongly reduced LTD. This was in contrast to $\mathrm{KO}$ where LTD could be restored by blocking GluN2B. Thus, we suggest that the GluN2B is hyperactive in the KO and by dampening its function mGluR-LTD can be rescued.

\section{Materials and Methods}

Animals. We used male Fmr1 KO mice ( $F m r-1^{-1 y}$, RRID:IMSR_JAX: 003025, The Jackson Laboratory), and the C57BL/6 WT mice for this study. The Fmr1 KO mouse was bred in C57BL/6J background in a nonlittermate fashion. Four different age groups were used: pups, p15p21; juvenile, p30-p40; young adult, p60-p80; and one mature adult group, $p>120$ (p120-p200). All animals were kept on a 12:12 h light/ dark cycle with a constant room temperature. The mice were housed in groups and provided with ad libitum food and water. The animal experiments were conducted in accordance with the animal care guidelines of Aarhus University.

Slice preparation. The animals were deeply anesthetized with isoflurane and decapitated. The brains were rapidly removed and placed in ice-cold slicing solution equilibrated with $95 \% \mathrm{O}_{2} / 5 \% \mathrm{CO}_{2}$ mixture, $\mathrm{pH}$ $7.4 ; 300 \mu \mathrm{m}$ coronal slices were prepared with a Leica VT1200S vibrating microtome. To test for involvement of excitatory inputs from CA3, in approximately one-third of the experiments, CA3 was surgically removed immediately after sectioning. No significant difference in DHPGinduced LTD was observed in experiments where CA3 was cutoff versus not cutoff. Slicing solution was composed of the following (in $\mathrm{mM}$ ): 93 $N$-methyl-D-glucamine, $93 \mathrm{HCl}, 2.5 \mathrm{KCl}, 1.2 \mathrm{NaH}_{2} \mathrm{PO}_{4}, 30 \mathrm{NaHCO}_{3}, 20$ HEPES, 25 D-glucose, 5 ascorbic acid, $10 \mathrm{MgCl}_{2}$, and $0.5 \mathrm{CaCl}_{2}$. After cutting, the slices recovered at $34^{\circ} \mathrm{C}$ in aCSF (in mM) as follows: $124 \mathrm{NaCl}$, $2.5 \mathrm{KCl}, 1.2 \mathrm{NaH}_{2} \mathrm{PO}_{4}, 24 \mathrm{NaHCO}_{3}, 5$ HEPES, 12.5 D-glucose (in some experiments, $5 \mathrm{~N}$-acetyl-L-cysteine was added), $2 \mathrm{CaCl}_{2}$, and $2 \mathrm{MgCl}_{2}$. After $10 \mathrm{~min}$, the slices were placed in aCSF at room temperature for an additional $1-2 \mathrm{~h}$.

Electrophysiology. Individual slices were placed in an interface tissue slice chamber (BSC2, Scientific System Design), where the temperature was maintained at $30.0 \pm 0.3^{\circ} \mathrm{C}$. The slices were superfused with carbogenated aCSF with a flow rate through the chamber of $2.5 \mathrm{ml} / \mathrm{min}$ set with a peristaltic pump. After transfer to the chamber, the slices were allowed to rest for an additional $60 \mathrm{~min}$ before starting the experiment. A bipolar stimulating electrode made from twisted nichrome wire $(66 \mu \mathrm{m}$; A-M Systems) was placed on the surface of the stratum radiatum of area CA1 to orthodromically stimulate the Schaffer collateral/commissural fibers. Dendritic field EPSPs (fEPSPs) were recorded in stratum radiatum of CA1 using a glass micropipette filled with $2 \mathrm{M} \mathrm{NaCl}$ with an electrode resistance of $4-6 \mathrm{M} \Omega$. Dendritic fEPSPs were evoked with a paired-pulse stimulation using an interstimulus interval of $25 \mathrm{~ms}$ with stimulation intensity between 50 and $150 \mu \mathrm{A}$, yielding a fEPSP of $\sim 50 \%$ of maximum response. Recordings were collected every $20 \mathrm{~s}$ and were low-pass filtered set at $1 \mathrm{kHz}$ and amplified with a differential AC amplifier model 1700 (A-M Systems). fEPSP slopes were measured and analyzed from digitized EPSPs (NacGather 2.0, Theta Burst). Drugs or LTD-inducing stimuli were not applied until after a stable baseline was achieved for at least $20 \mathrm{~min}$.

mGluR-dependent LTD was induced either by bath application of DHPG $(100 \mu \mathrm{M})$ for $10 \mathrm{~min}$ or by pair-pulse low-frequency stimulation (PP-LHS). PP-LHS was induced by applying $9001 \mathrm{~Hz}$ double pulses (separated by $50 \mathrm{~ms}$ ).

NMDAR-dependent LTD was induced by LHS (900 $1 \mathrm{~Hz}$ single pulses). LHS and PP-LHS were done under identical conditions as with DHPG-induced mGluR-LTD, with the only exception that extracellular magnesium was lowered to $1.5 \mathrm{~mm}$.

Overall, the recordings were done in the presence or absence of different NMDAR antagonists: APV $(50 \mu \mathrm{M}),(5 S, 10 R)-(+)-5$-methyl-10,11dihydro-5H-dibenzo $[a, d]$ cyclohepten-5,10-imine maleate (MK-801; 20 $\mu \mathrm{M}),(1 \mathrm{~S}, 2 \mathrm{~S})-1-(4$-hydroxy-phenyl)-2-(4-hydroxy-4-phenylpiperidino)-1propanol (CP-101606, $1 \mu \mathrm{M}),(\alpha R, \beta S)$ - $\alpha$-(4-hydroxyphenyl)- $\beta$-methyl-4(phenylmethyl)-1-piperidinepropanol maleate (RO25-6981, $1 \mu \mathrm{M}$ ), and 3-chloro-4-fluoro- $\mathrm{N}$-[4-[[2-(phenylcarbonyl)hydrazino] carbonyl] benzylbenzenesulfonamide (TCN-201, $10 \mu \mathrm{M})$. All chemicals used were acquired from either Tocris Bioscience or Sigma-Aldrich. For the MK-801 experiments, slices were treated with MK-801 for 20-30 min during normal stimulation, followed by a $30 \mathrm{~min}$ wash period without stimulation. After the wash period, stimulation was resumed; and after 20 min baseline, LTD was induced by application of DHPG.

Biochemistry. Mouse hippocampus was rapidly dissected and flash frozen in liquid nitrogen and subsequent stored at $-80^{\circ} \mathrm{C}$ until use. Protein samples were purified in pairs (WT and $\mathrm{KO}$ ) (from a total number of 28 hippocampi isolated from 5 WT and 9 KO mice, p60-p80). Samples were prepared by homogenizing the tissue in 10 volumes of ice-cold RIPA buffer ( 25 mм Tris-HCl, pH 7.6, $150 \mathrm{~mm} \mathrm{NaCl}, 5$ mм EDTA, 1\% Triton $\mathrm{X}-100,1 \%$ sodium deoxycholate, $0.1 \%$ SDS) with protease and phosphatase inhibitors included and incubated an additional $1-2 \mathrm{~h}$ on ice. Samples were centrifuged at $14,000 \times g$ for $30 \mathrm{~min}$, and the precipitate was discarded. Samples were boiled for $5 \mathrm{~min}$ in sample buffer before loading of $30 \mu \mathrm{g}$ protein onto $10 \%$ Tris- $\mathrm{HCl}$ gels (Bio-Rad) and electrophoresed at $100 \mathrm{~V}$ for $\sim 90 \mathrm{~min}$, resolved by SDS-PAGE, and semidry transferred (Bio-Rad) to PVDF membranes for 45-60 min at $25 \mathrm{~V}$. Blots were blocked in $1 \times$ casein buffer (Sigma, B6429) for $1 \mathrm{~h}$ and incubated with 
A
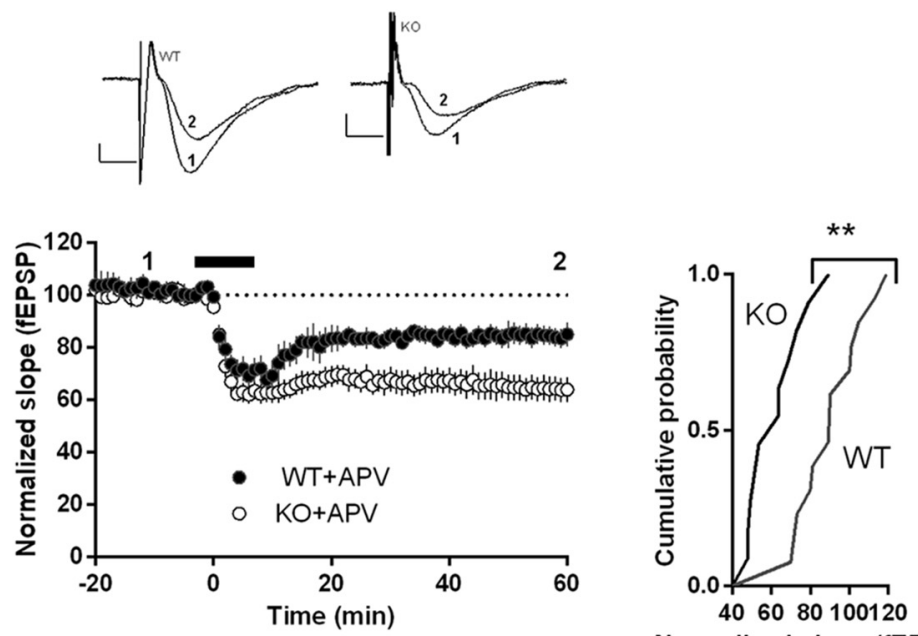

Normalized slope (fEPSP)

B
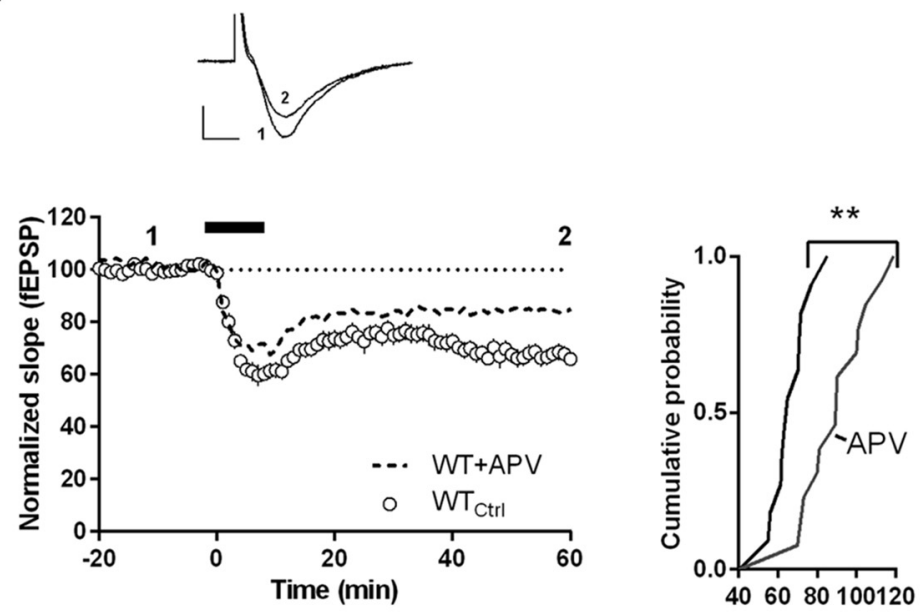

Normalized slope (fEPSP)

C

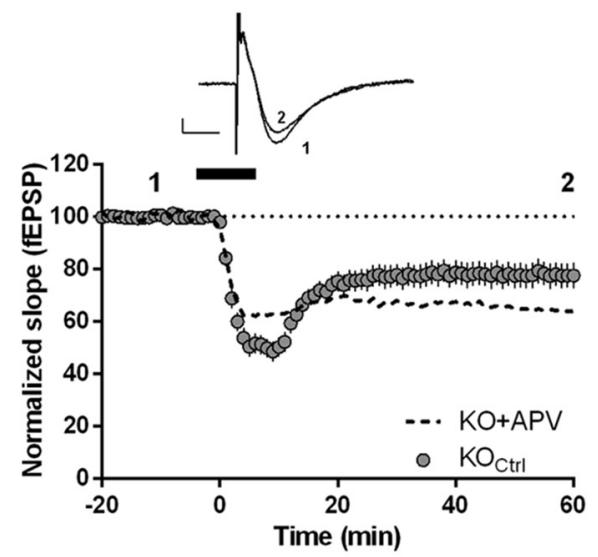

primary antibody overnight at $4^{\circ} \mathrm{C}$ followed by secondary antibody $1 \mathrm{~h}$ at room temperature. For imaging, the GeneSys Pxi4 system was used following manufacturer's protocols, and bands were quantitated and normalized relative to the expression of $\beta$-actin using ImageJ software (National Institutes of Health). The following antibodies from Abcam were used: rabbit antiNMDAR2A (1:1000, Abcam catalog \#ab133265, RRID:AB_11158532), rabbit anti-NMDAR2B (1:1000, Abcam catalog \#ab65783, RRID: AB_1658870), rabbit anti-NMDAR1 (1:1000, Abcam catalog \#ab109182, RRID:AB_1086 2307), rabbit anti- $\beta$ actin (1:2000, Abcam catalog \#ab8227, RRID:AB_2305186), and chicken antirabbit IgG (HRP) (1:2000, Abcam catalog \#ab6829, RRID:AB_955444).

Data analysis and statistics. The data were analyzed by expressing the slope of the fEPSP as a percentage of the precondition baseline. The time scale of each experiment was adjusted to the time from the onset of DHPG. The time match normalized data were averaged across experiments and expressed as mean \pm SEM. For clarity of presentation, three data points were averaged and represented as one point in each individual experiment before the mean across experiments was done. Where stated, $n$ represents the number of slices used in each experiment, and a minimum of 3 animals were used per each experiment.

All statistical analysis was performed using GraphPad Prism 6 (GraphPad Software). Significant differences between groups were tested using Student's $t$ tests or Kolmogorov-Smirnov test when appropriate.

\section{Results}

mGluR-LTD

The Schaffer collateral-CA1 pyramidal cell synapse is one of the best understood synapses in the mammalian brain and exhibits both NMDAR-LTD (Dudek and Bear, 1992; Mulkey and Malenka, 1992) and mGluR-LTD (Bolshakov and Siegelbaum, 1994; Oliet et al., 1997). To confirm previous findings in mGluR-LTD, we started recording from p30-p40 mice. Figure $1 A$ shows that, after collecting stable baseline responses, LTD was induced by bath applying the selective mGluR Group 1 agonist, DHPG, for $10 \mathrm{~min}$ on excitatory synaptic transmission in CA1 in p30-p40 WT and $\mathrm{KO}$ acute slices. DHPG transiently reduced synaptic re-

$\leftarrow$

represents $5 \mathrm{~ms} ; y$-axis represents $0.2 \mathrm{mV}$. C, Left, Mean fEPSP slope of mGluR-dependent LTD in the absence of APV in Fmr 1 $\mathrm{KO}$ age $\mathrm{p30}-\mathrm{p} 40$. Superimposed on the figure is LTD in the presence of APV (dotted line, from from $A$ ). There was no significant difference in LTD $\pm A P V$ at 60 min after application of DHPG. Bars represent SEM. Inset, Representative traces of $\mathrm{KO}_{\mathrm{C}}$ trl at indicated time points. Right, Cumulative plots of normalized slope (fEPSP) from left. $x$-axis represents $5 \mathrm{~ms} ; y$-axis represents $0.2 \mathrm{mV}$. ns, Not significant.
Figure 1. DHPG-induced LTD in WT and Fmr1 K0 mice. A, Induction of LTD by bath application of $100 \mu \mathrm{m}$ DHPG for 10 min (indicated with a black line at the top of the traces) in the presence of the NMDAR antagonist, APV. Left, Mean fEPSP slope of mGluR-dependent LTD in age p30 -p40 WT and Fmr $1 \mathrm{KO}$ shows a significant exaggeration of depression in KO compared with WT after $60 \mathrm{~min}(p<0.01)$. Inset, Representative traces from indicated time points. Left, WT. Right, K0. $x$-axis represents $5 \mathrm{~ms} ; y$-axis represents $0.2 \mathrm{mV}$. Right, cumulative plots of normalized slope (fEPSP; data from $\boldsymbol{A}$ ). ${ }^{* *} p<0.01$. $\boldsymbol{B}$, Left, Mean fEPSP slope of mGluR-dependent LTD in WT age p30 -p40 in the absence of APV. Superimposed on the figure is LTD with APV (dotted line, from A). At 60 min after DHPH application, there is significantly more depression in WT without APV than with APV $(p<0.01)$. Inset Representative traces of $\mathrm{WT}_{\mathrm{Ctrl}}$ at indicated time points. Right, Cumulative plots of normalized slope (fEPSP) from left. $x$-axis 
Table 1. mGluR-LTD and mGluR-MTD in WT and Fmr1KO

\begin{tabular}{|c|c|c|c|c|c|c|c|c|c|}
\hline \multirow[b]{3}{*}{ Age groups } & \multirow[b]{3}{*}{ APV } & \multicolumn{3}{|l|}{ WT } & \multicolumn{5}{|l|}{ KO } \\
\hline & & MTD & LTD & & MTD & & LTD & & \\
\hline & & $\%$ & $\%$ & $n$ & $\%$ & $p$ & $\%$ & $n$ & $p$ \\
\hline \multirow[t]{2}{*}{ p15-21 } & + & $37 \pm 4$ & $30 \pm 4$ & 14.6 & $50 \pm 3$ & 0.003 & $26 \pm 4$ & 17.6 & NS \\
\hline & - & $48 \pm 3$ & $19 \pm 5$ & 13.5 & $53 \pm 5$ & NS & $25 \pm 4$ & 15.6 & NS \\
\hline \multirow[t]{2}{*}{ p30-40 } & + & $31 \pm 4$ & $23 \pm 3$ & 13.8 & $36 \pm 2$ & NS & $37 \pm 4$ & 12.6 & 0.001 \\
\hline & - & $40 \pm 5$ & $33 \pm 3$ & 14.9 & $50 \pm 5$ & NS & $22 \pm 5$ & 24.10 & 0.02 \\
\hline \multirow[t]{2}{*}{ p60-80 } & + & $36 \pm 3$ & $24 \pm 5$ & 15.7 & $40 \pm 5$ & NS & $38 \pm 3$ & 12.6 & 0.02 \\
\hline & - & $42 \pm 6$ & $28 \pm 5$ & 12.6 & $20 \pm 6$ & 0.02 & $5 \pm 4$ & 15.4 & 0.001 \\
\hline \multirow[t]{2}{*}{$>\mathrm{p} 120$} & + & $24 \pm 5$ & $27 \pm 4$ & 17.8 & $29 \pm 4$ & NS & $21 \pm 4$ & 13.6 & NS \\
\hline & - & $30 \pm 4$ & $19 \pm 5$ & 19.8 & $26 \pm 4$ & NS & $8 \pm 5$ & 18.8 & 0.03 \\
\hline
\end{tabular}

$n$, Number of experiments/animals (e.g., $8.4=8$ slices from 4 animals). $p$, Student's t test $\left(\mathrm{KO}_{\mathrm{MTD}} \mathrm{VS} \mathrm{WT}_{\mathrm{MTD}}\right.$ and $\left.\mathrm{KO}_{\mathrm{LTD}} \mathrm{VS} \mathrm{WT}_{\mathrm{LTD}}\right) ; \mathrm{NS}$, not significant; $\mathrm{S}-\mathrm{W}$, Shapiro-Wilk normality test with $\alpha=0.05$ : all data passed the S-W normality test.

A
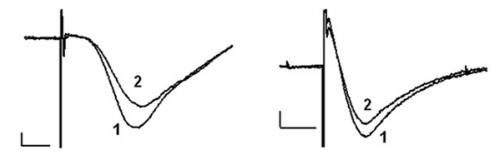

B

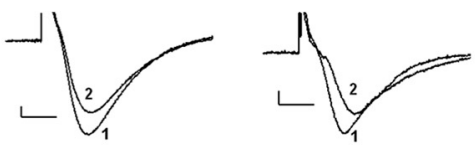

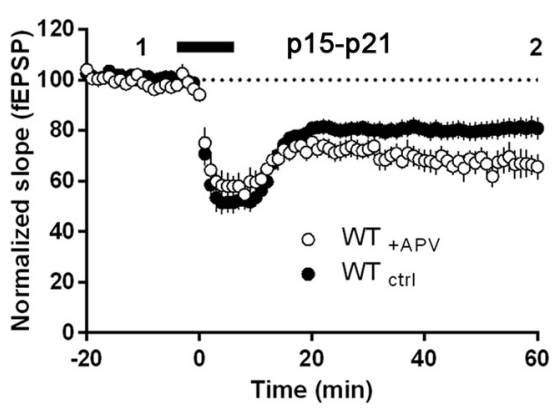

C

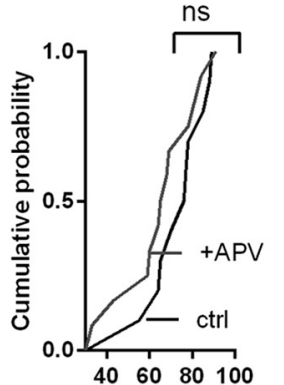

Normalized slope (fEPSP)
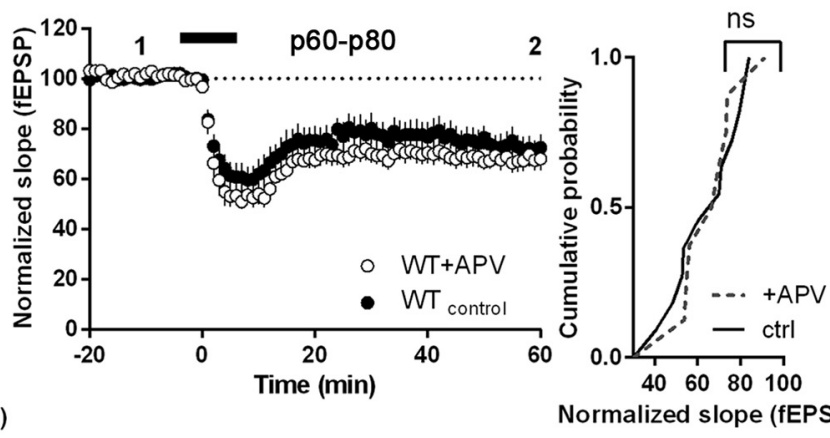

Normalized slope (fEPSP)
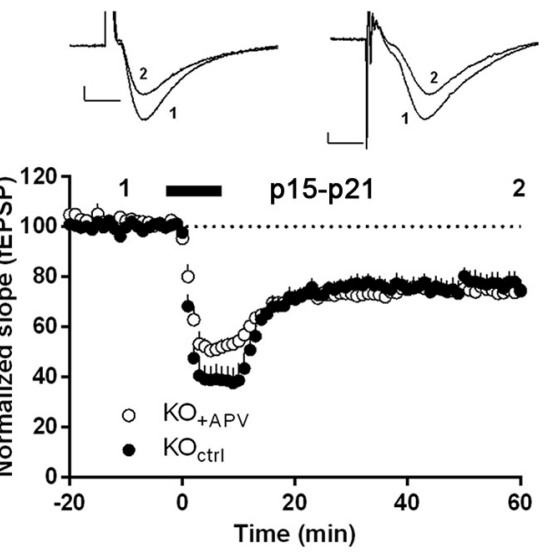

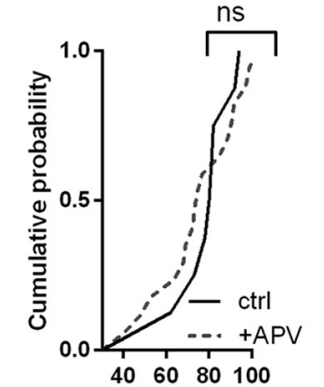

Normalized slope (fEPSP)
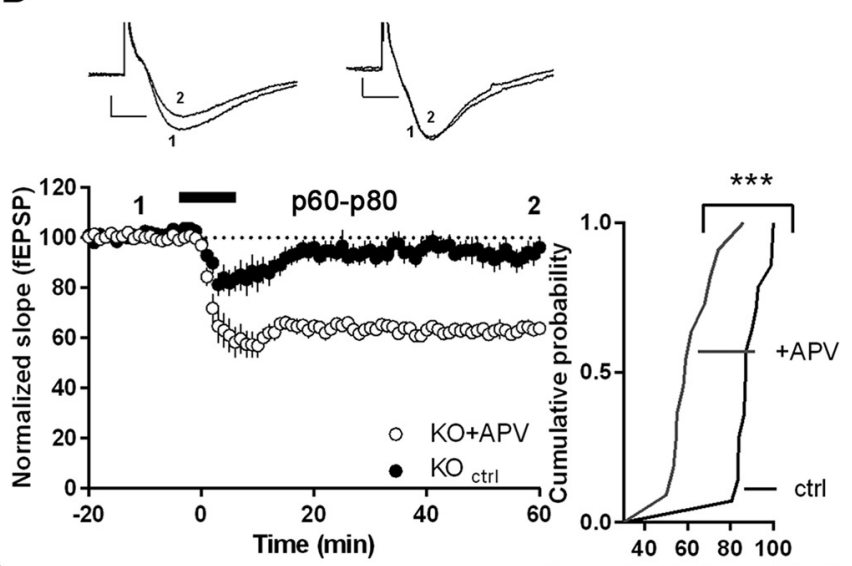

Normalized slope (fEPSP)

Figure 2. Fmr $1 \mathrm{KO}$ shows altered mGluR-dependent LTD with active NMDARs. $\boldsymbol{A}, \boldsymbol{C}$, Mean fEPSP slope of mGluR-dependent LTD in WT $(\boldsymbol{A})$ and K0 ( $\boldsymbol{C})$ age p15-p21 shows no significant difference with or without APV after $60 \mathrm{~min}(p>0.05)$. Inset, Representative traces from indicated time points. Left traces, control. Right traces, + APV. $x$-axis represents $5 \mathrm{~ms} ; y$-axis represents $0.2 \mathrm{mV}$. $\boldsymbol{B}$, D, Mean fEPSP slope of mGluR-dependent LTD in WT age p60-p80 shows no significant difference with or without APV after 60 min $(p>0.05)$, whereas in age-matched Fmr 1 K0 (D), a clear statistically significant difference is seen between mGluR-dependent LTD recorded in the presence or absence of APV $(p<0.001)$. Insets, Representative traces from indicated time points. Left traces, + APV. Right traces, control. Right, Cumulative plots of normalized slope (fEPSP) from $A-D$, respectively. ${ }^{* *} p<0.001$. ns, Not significant.

sponses, called maximal transient depression (MTD) and after removal of DHPG, MTD was followed by a recovery and a relaxation phase. This stable response was depressed in relation to its initial baseline response (i.e., LTD). This form of LTD did not depend upon activation of NMDARs as it was induced in the presence of the NMDAR antagonist APV $(50 \mu \mathrm{M})$. Consistent with other groups (Huber et al., 2002; Michalon et al., 2014), we found, on average, in WT that the lasting depression of synaptic strength was significantly less than in Fmr $1 \mathrm{KO}(23 \pm 3 \%, n=13$ vs $37 \pm 4 \%, n=12 ; p=0.001$ ) (Fig. $1 A$; Table 1 ). In the presence 
A
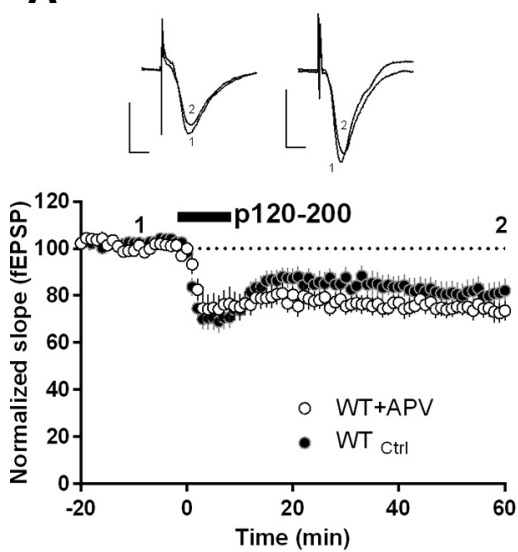

C

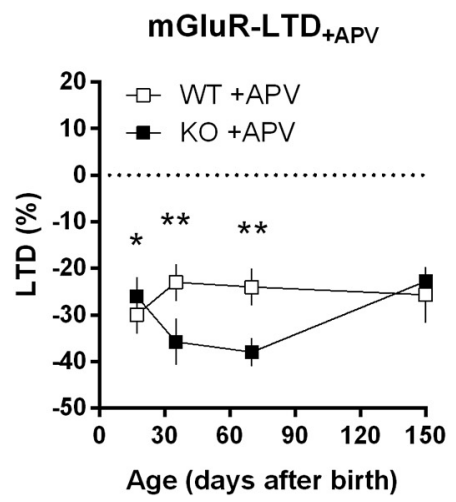

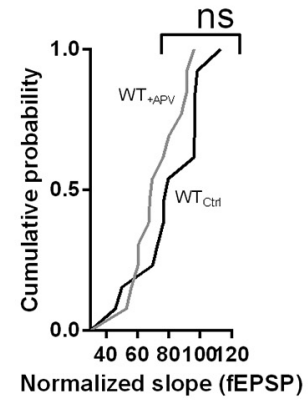

D

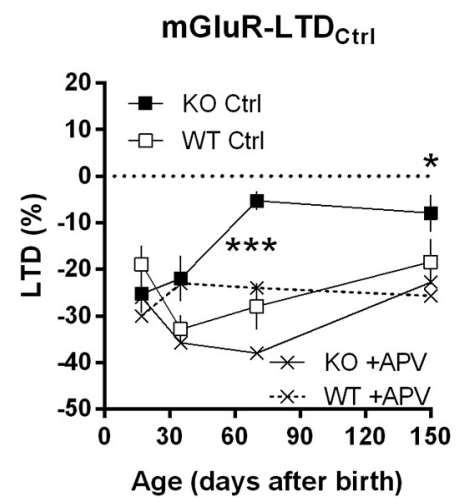

B
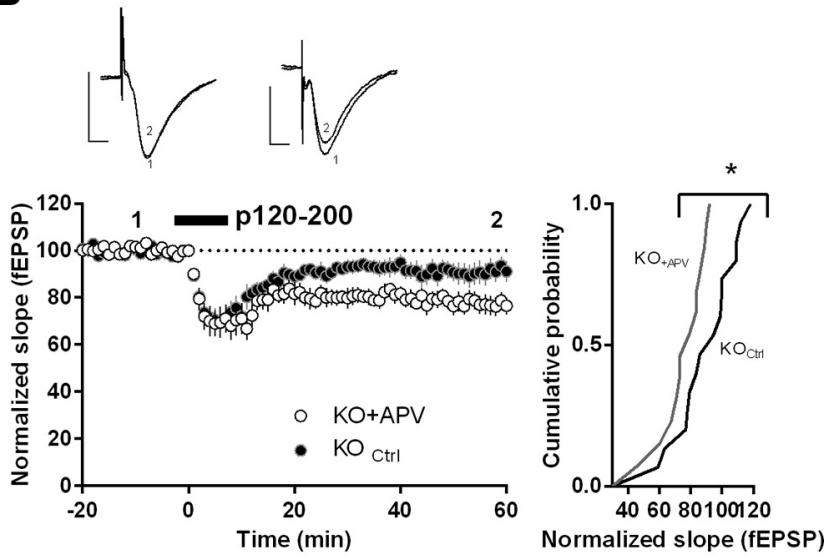

E

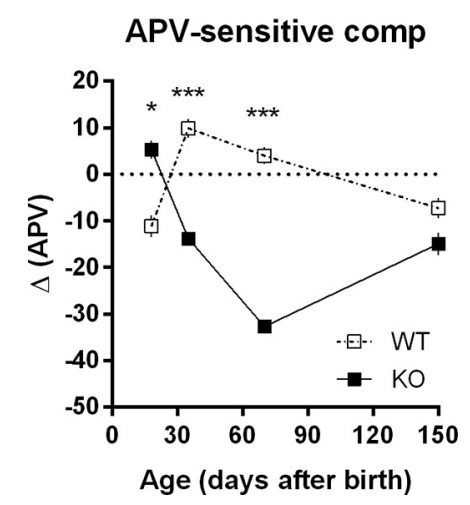

Figure 3. In the absence of APV, a time-dependent gap emerged in Fmr 1 K0 between 1 and 6 month of age. $\boldsymbol{A}, \boldsymbol{B}$, Left, Mean fEPSP slope of mGluR-dependent LTD in WT ( $\mathrm{p} 120$-p200) shows no significant difference with or without APV after $60 \mathrm{~min}(p>0.05)$; whereas in the Fmr $1 \mathrm{KO}$ (p120-p200; $\boldsymbol{B})$, there is a statistical difference in depression after 60 min $(p<0.05)$. Insets above plots, Representative traces from indicated time points (left traces, control; right traces, + APV). $x$-axis represents $5 \mathrm{~ms} ; y$-axis represents $1 \mathrm{mV}$. $\boldsymbol{A}, \boldsymbol{B}$, Right, Cumulative plots of normalized slope (fEPSP) from $\boldsymbol{A}, \boldsymbol{B}$. C, Graphical representation of the changes in mGluR-LTD in the presence of APV in WT and Fmr 1 K0 throughout development. ${ }^{*} p<0.05$. ${ }^{* *} p<0.01$. D, Graphical representation of the total amount changes in mGluR-LTD in the absence of APV in WT and Fmr 1 KO throughout development. Superimposed on figure is data from K0 and WT in the presence of APV (from $C$ ). ${ }^{*} p<0.05$. ${ }^{* * *} p<0.001$. E, Plot of NMDAR residual LTD obtained at time point 60 min after DHPG application at different developmental ages. Student's $t$ test between WT versus K0: ${ }^{*} p<0.05,{ }^{* * *} p<0.001$. ns, Not significant.

of APV, the MTD were $31 \pm 4(n=13)$ and $36 \pm 2(n=12)(p=$ 0.3 ) in WT and $\mathrm{KO}$, respectively (Table 1 ). The statistical significance was further confirmed with a Kolmogorov-Smirnov test of the cumulative probability distribution ( $p<0.05$; Fig. $1 A)$. As expected, in the absence of APV, LTD was increased to $33 \pm 3 \%$ (Fig. $1 B ; p<0.05$; Table 1 ) in WT p30-p40; whereas in the $\mathrm{KO}$ mice, recordings in the absence of APV were decreased to $22 \pm$ $5 \%$ (Fig. $1 C ; p=0.02$; Table 1 ), supporting a role for NMDARs in the induction of mGluR-mediated LTD at this development stage.

We repeated these experiments in the early juvenile WT and KO (p15-p21) group. In the presence or absence of APV, LTD was not significantly different in either the WT or $\mathrm{KO}(30 \pm 4 \%$ vs $26 \pm 4 \%$ in WT and $\mathrm{KO}$ in the presence and $19 \pm 5 \%$ vs $25 \pm$ $4 \%$ in WT and KO in the absence of APV; Fig. 2A, C; Table 1).

In contrast to slices made from the WT p60-p80 group where APV had no apparent effect on mGluR-LTD ( $24 \pm 5 \%$ vs $28 \pm$ $5 \%$ in the presence and absence of APV, respectively), in $\mathrm{KO}$, APV had a strong significant effect (Fig. 2B,D). Thus, recording in slices from the KO in the absence of APV revealed a very small amount of DHPG-induced LTD $(5 \pm 4 \%, n=15)$. Interestingly, application of APV restored mGluR-LTD in the KO mouse completely $(38 \pm 3 \%, p<0.001 ; n=12)$ to the same magnitude seen with slices prepared from p30-p40 mice (Fig. 1). In a series of control experiments, using the open NMDAR channel blocker, MK-801, mGluR-LTD was identical to values obtained with application of APV: $32 \pm 8 \%(n=7)$ in WT (p60-p80) and $27 \pm 5 \%$ $(n=5, p>0.05)$ in $\mathrm{KO}$ (p60-p80) (data not shown).

In slices made from WT $p>120$ in the absence of APV, LTD was $19 \pm 5 \%$. Although not quite significant, a small enhanced LTD trend was observed after application of APV $(27 \pm 4 \%, p>$ 0.05 ; Fig. $3 A$ ). In the absence of APV, LTD in the KO mouse ( $p>$ $120)$ was $8 \pm 5 \%$. Significantly enhanced LTD was found in the KO after application of APV $(21 \pm 4 \%$; $p=0.02$; Fig. $3 B)$.

These results strongly suggest that NMDARs play an as yet unknown but vital role in mGluR-dependent LTD. Figure $3 C$ shows the amount of DHPG-induced LTD in the presence of APV $\left(\mathrm{mGluR}_{\mathrm{LTD}} \mathrm{APV}_{\text {APV }}\right)$ plotted versus age. Here a clear and strong significant difference in the mGluR component was observed in the p15-p21, p30-p40, and p60-p80 populations; however, only in the two p30-p40 and p60-p80 populations were there enhanced LTD in the KO. In older mice, no difference was found. On the other hand, plotting LTD, obtained in the absence of APV (mGluR-LTD Ctrl $_{1}$ ), revealed a clear age-dependent shift in mGluR-LTD in both WT and KO. Thus, in WT, strong mGluR-LTD $\mathrm{Ctrl}_{\text {was }}$ observed peaking in the p30-p40 population where after a decline in GluR-LTD $_{\text {Ctrl }}$ take 
A

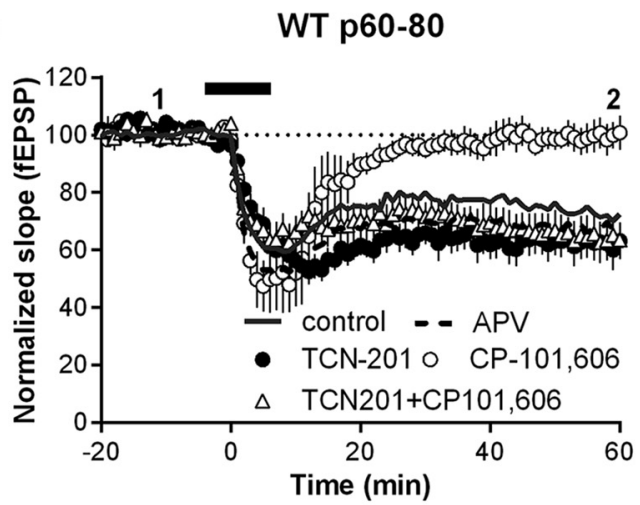

B

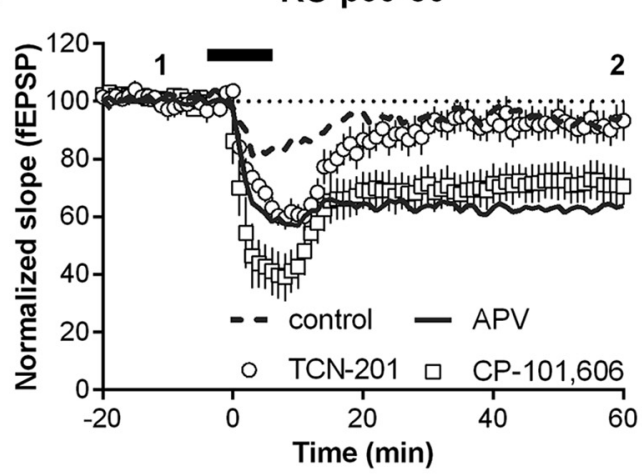

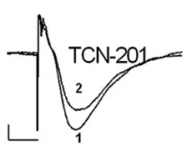
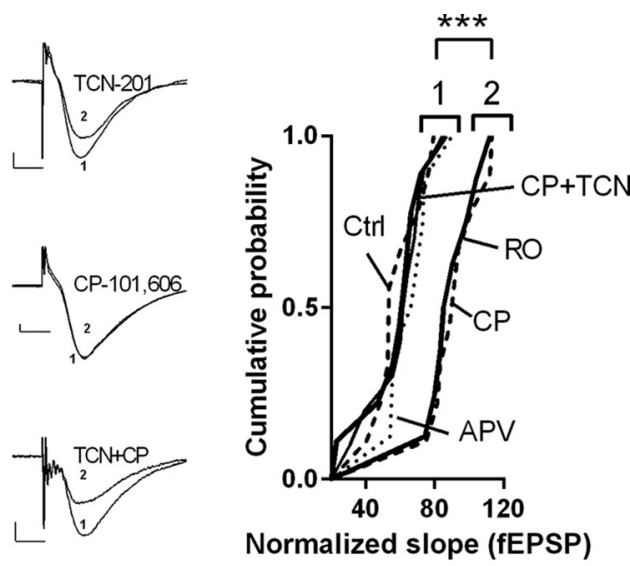

Normalized slope (fEPSP)

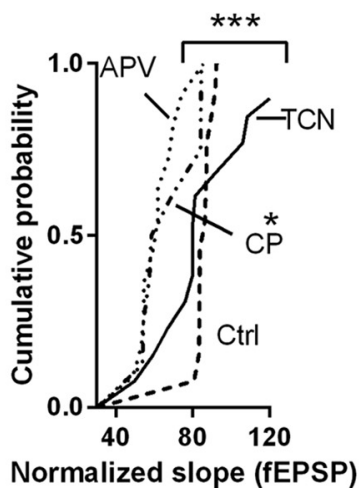

Figure 4. NMDAR subunit-specific GluN2B antagonist blocks LTD in WT but rescue LTD in K0. $A$, Mean fEPSP slope of mGluR-dependent LTD in the WT (age p60-p80) in the presence of either the GluN2A antagonist, TCN-201 (10 $\mu \mathrm{M})$, or the GluN2B antagonist, (P-101606 (1 $\mu \mathrm{M})$, and compared with control (in the absence of APV) and LTD in the presence of APV. Application of CP-101606 blocks LTD ( $p<0.001)$, whereas no difference was observed with application of TCN-201 ( $p>0.05)$. Coapplication of CP-101606 and TCN-201 restored LTD to control level. Insets, Representative traces from indicated time points. $x$-axis represents $5 \mathrm{~ms} ; y$-axis represents $0.2 \mathrm{mV}$. Right, Cumulative plots of normalized slope (fEPSP) from $\boldsymbol{A}$ (1: thick line indicates TCN-201; dotted line indicates APV, thick dotted line indicates control; 2: thick line indicates R025-6981 [mean fEPSP slope not shown]; thick dotted line indicates (P-101606). There was no significant difference between data within Group 1 or Group 2. ${ }^{* *} p<0.001$, significant difference between data between Group 1 and Group 2. B, Left, Mean fEPSP slope of mGluR-dependent LTD in the Fmr 1 K0 age p60-p80 in the presence of TCN-201 $(10 \mu \mathrm{M})$ or (P-101606 $(1 \mu \mathrm{M})$ and compared with control (in the absence of APV) and in the presence of APV. CP-101606, but not TCN-201, restores LTD to the same level as with APV. Insets, Representative traces from indicated time points. $x$-axis represents $5 \mathrm{~ms} ; y$-axis represents $0.2 \mathrm{mV}$. Right, Cumulative plots of normalized slope (fEPSP). Thick dotted line indicates control (K0). Dotted line indicates APV. Medium dotted line indicates (P-101606. Thick line indicates TCN-201. Significant difference between control and APV, and TCN-201 and APV $(* * * p<0.001)$ and between (P-101606 and control $\left({ }^{*} p<0.05\right)$.

off. However, a much more pronounced decline in the $\mathrm{KO}$ animal in mGluR-LTD $\mathrm{Ctrl}_{\text {was }}$ observed starting earlier than in WT, here also peaking $\sim$ p30 (Fig. $3 D$ ). In addition, in the KO, mGluR-LTD $\mathrm{Ctrl}_{\text {is }}$ almost completely gone between p70 and p120, creating a broad time window, where $\mathrm{KO}$ has significantly less mGluR-LTD than WT.

Interestingly, superimposing $\mathrm{KO}$ and WT data from mGluR$\mathrm{LTD}_{+\mathrm{APV}}$ onto Figure $3 \mathrm{D}$ revealed that developmentally the KO recapitulates the WT when NMDARs are blocked. Thus, these data combined, strongly arguing for overstimulated NMDARs in the KO during this period of time from early development to fully mature mouse.

\section{The NMDAR component in mGluR-LTD}

Subtracting mGluR-LTD + APV from mGluR-LTD Ctrl $_{\text {reveals the }}$ APV-sensitive component $(\triangle \mathrm{APV})$. Figure $3 E$ shows the APVsensitive component plotted against age. In WT, a clear "peak" appears early in development $(\sim$ p30-p60) in $\Delta$ APV where after the "peak" shifts direction. In contrast, except at pre-p30, the NMDAR component in the KO remains significantly stronger and negative throughout development until $p>120$ where $\mathrm{KO}$ and WT tend to come together. In summary, these data point toward a model where mGluR-dependent LTD is under strong developmental NMDAR regulation for the first several months of the mouse's life.

\section{NMDAR subtype-dependent LTD}

This clear NMDAR-dependent LTD difference observed in the p60-p80 age group (Figs. $2 B, D, 3 E$ ), raises the question of what type of NMDAR subtypes might be responsible for this difference. It is well known that the predominantly expressed types of NMDARs in the brain are GluN2A- and GluN2B-containing channels (Wyllie et al., 2013). We therefore took advantage of the GluR2A- and GluN2B-selective antagonists, TCN-201 and CP-101606, respectively, and tested them in our DHPG-induced mGluR-LTD assay. In WT in the p60-p80 group, blocking GluN2A-containing NMDARs had no apparent effect on DHPG-LTD. In contrast, antagonizing GluN2B channels with CP-101606 completely blocked DHPG-induced LTD $(1 \pm 6 ; n=$ 12; Fig. $4 A$ ). In a series of control experiments, using another GluN2B antagonist, RO 25-6981, had similar effect on WT: $8 \pm$ $4 \%(n=8$; data not shown). Interestingly, blocking both GluN2A and Glu2B by coapplication of both TCN-201 and CP-101606 fully restored LTD to the values observed by APV (Fig. 4A). 
A
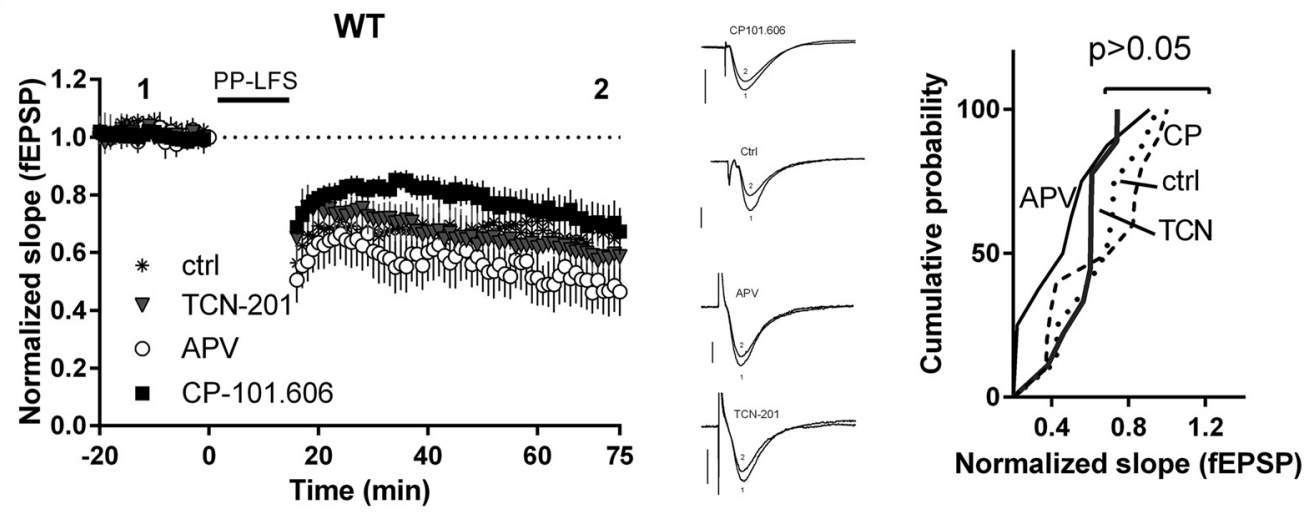

B
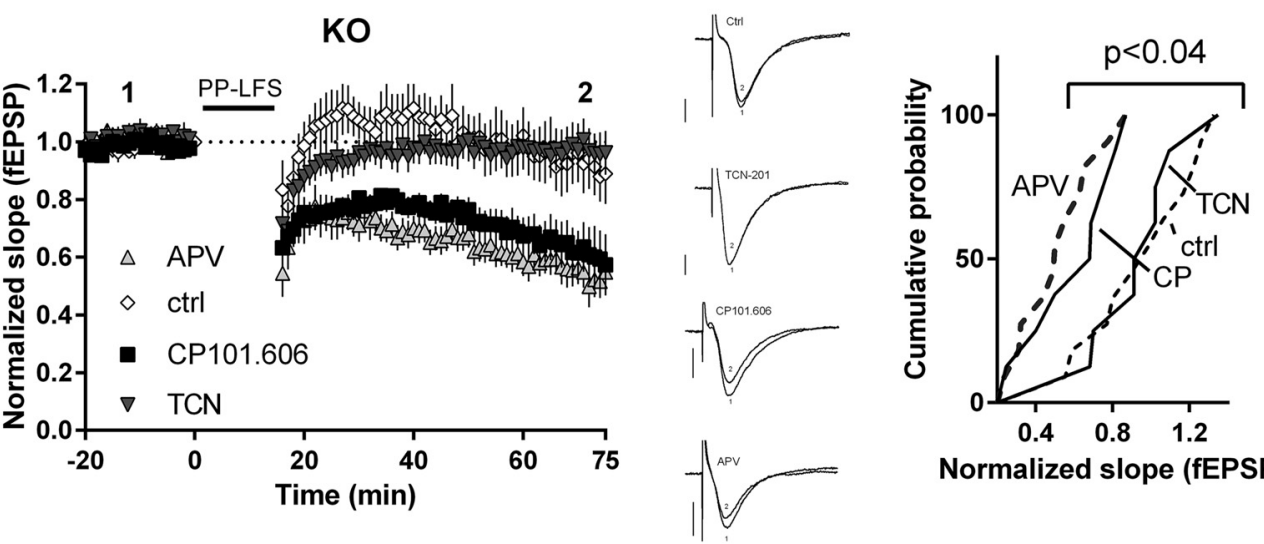

Normalized slope (fEPSP)

Figure 5. Synaptically induced mGluR-LTD in K0 is comparable with DHPG-induced mGluR-LTD. A, Left, Mean fEPSP slope of PP-LFS-induced LTD in the WT (age p60-p80) in the presence of either the GluN2A antagonist, TCN-201 (10 $\mu \mathrm{m})$, or the GluN2B antagonist, (P-101606 $(1 \mu \mathrm{m})$, and compared with control (in the absence of APV) and LTD in the presence of APV. Insets, Examples of raw traces from indicated time points. $y$-axis represents $0.5 \mathrm{mV}$. Right, Cumulative plots of normalized slope (fEPSP) from $\boldsymbol{A}$. No significant difference between data $(p>0.05)$. $\boldsymbol{B}$, Left, Mean fEPSP slope of PP-LFS-induced LTD in the K0 (age p60-p80) in the presence of either the GluN2A antagonist, TCN-201 (10 $\mu \mathrm{M})$, or the GluN2B antagonist, (P-101606 (1 $\mu \mathrm{M})$, and compared with control (in the absence of APV) and LTD in the presence of APV. Insets, Examples of raw traces from indicated time points. $y$-axis represents $0.5 \mathrm{mV}$. Right, (umulative plots of normalized slope (fEPSP) from $\boldsymbol{B}$. No significant difference between data within APV and (P-101606, and TCN-201 and control treated slices. ${ }^{*} p<0.04$, significant difference between ctrl or TCN-201 and CP-101606 or APV-treated slices.

Table 2. LFS and PP-LFS induced LTD in P60-80 WT and Fmr1KO

\begin{tabular}{|c|c|c|c|c|c|}
\hline & LTD WT (\%) & $n$ & LTD KO (\%) & $n$ & $p$ \\
\hline \multicolumn{6}{|l|}{ LFS } \\
\hline Ctrl & $55 \pm 6$ & 14.4 & $22 \pm 7$ & 8.4 & 0.003 \\
\hline APV & $29 \pm 5$ & 10.4 & $18 \pm 6$ & 9.4 & NS \\
\hline TCN-201 & $47 \pm 4$ & 11.4 & $36 \pm 7$ & 12.4 & NS \\
\hline CP101606 & $20 \pm 6$ & 13.4 & $19 \pm 5$ & 9.4 & NS \\
\hline \multicolumn{6}{|l|}{ PP-LFS } \\
\hline Ctrl & $33 \pm 6$ & 8.3 & $4 \pm 9$ & 11.4 & 0.02 \\
\hline APV & $52 \pm 9$ & 8.3 & $47 \pm 6$ & 11.4 & NS \\
\hline TCN-201 & $41 \pm 4$ & 9.4 & $3 \pm 7$ & 8.3 & 0.001 \\
\hline CP101606 & $34 \pm 8$ & 9.4 & $40 \pm 10$ & 8.3 & NS \\
\hline
\end{tabular}

All recordings were performed in the $\mathrm{p} 60-80$ age group. $n$, Number of experiments/animals; $p$, Student's t test; NS, not significant; S-W, Shapiro-Wilk normality test with $\alpha=0.05$ : all data passed the S-W normality test.

This was in contrast in the KO mouse, where antagonizing GluN2B acted as APV, whereas application of the GluN2A antagonist blocked LTD to a similar degree as observed under control conditions (i.e., was without any apparent effect). These results suggest that blocking all or subtype-specific GluN2B NMDARs can rescue LTD in the $\mathrm{KO}$ animal. Furthermore, these results suggest that the GluN2A subunit has less influence on DHPGinduced mGluR-LTD than does the GluN2B subunit in both the $\mathrm{KO}$ and WT.

Next, instead of application of DHPG to introduce LTD, we repeated these experiments using a $1 \mathrm{~Hz}$ paired PP-LFS protocol.
This approach introduces a synaptic-specific mGluR-dependent form of LTD (Huber et al., 2002). Using this protocol, we obtained almost identical results as observed with the DHPGinduced LTD protocol (Fig. 5; Table 2). In the WT, application of APV, GluN2A, or GluN2B antagonists was without any clear effects; thus, in WT, using this protocol, no significant NMDAR dependency was observed. This was in contrast to $\mathrm{KO}$, where, in control conditions, no or only very little LTD was observed. This lack of LTD could be reversed by application of either APV or CP-101606, strongly suggesting that, in the KO, the PP-LFS protocol induces an NMDAR-dependent form of LTD. On the other 
A

WT
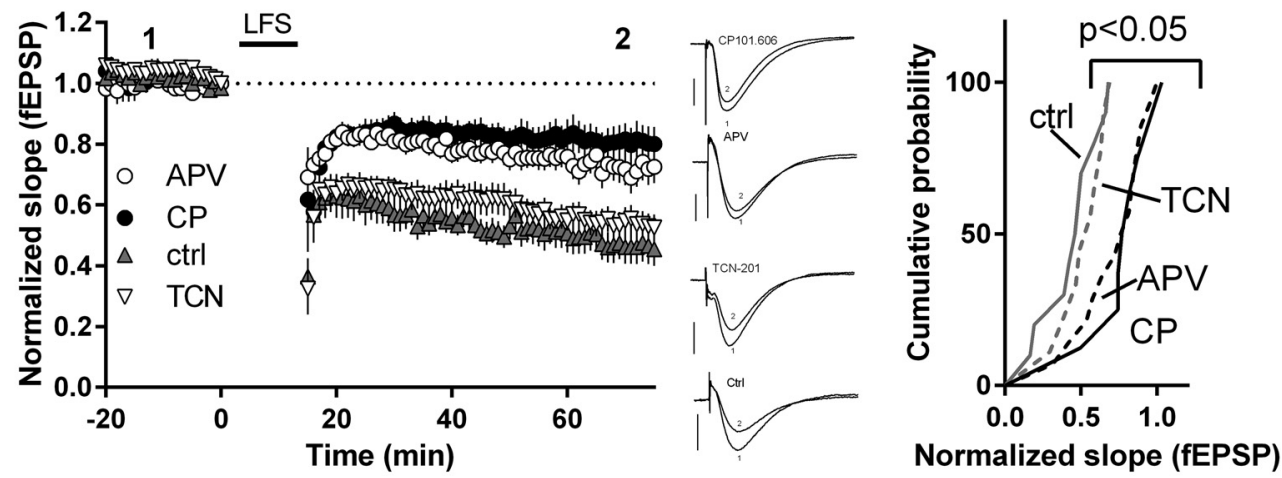

B
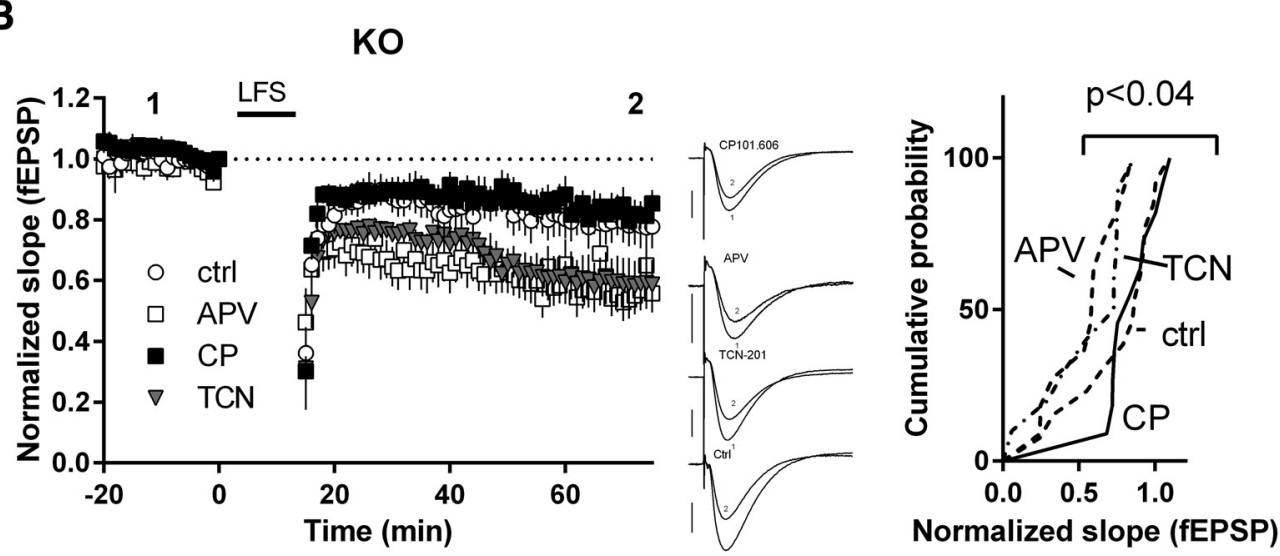

Figure 6. Synaptically induced NMDAR-dependent LTD in WT is comparable with DHPG-induced mGluR-LTD. A, Left, Mean fEPSP slope of LFS-induced LTD in the WT (age p60-p80) in the presence of either the GluN2A antagonist, TCN-201 (10 $\mu \mathrm{m})$, or the GluN2B antagonist, (P-101606 $(1 \mu \mathrm{M})$, and compared with control (in the absence of APV) and LTD in the presence of APV. Insets, Examples of raw traces from indicated time points. $y$-axis represents $0.5 \mathrm{mV}$. Right, Cumulative plots of normalized slope (fEPSP) from $A . p<0.05$, significant difference between data within APV and (P-101606, and TCN-201 and control treated slices. B, Left, Mean fEPSP slope of LFS-induced LTD in the K0 (age p60-p80) in the presence of either the GluN2A antagonist, TCN-201 (10 $\mu \mathrm{M}$ ), or the GluN2B antagonist, (P-101606 (1 $\mu \mathrm{M})$, and compared with control (in the absence of APV) and LTD in the presence of APV. Insets, Examples of raw traces from indicated time points. $y$-axis represents $0.5 \mathrm{mV}$. Right, Cumulative plots of normalized slope (fEPSP) from B. $p<0.04$, significant difference between ctrl and (P-101606, and APV and TCN-201.

hand, using a $1 \mathrm{~Hz}$ single-LFS protocol to induce LTD introduced clear NMDAR-dependent LTD in WT (Fig. 6; Table 2). Thus, application of either APV or CP-101606 inhibited LTD, resembling the results illustrated in Figure $4 A$. A similar but reversed result was observed in the $\mathrm{KO}$, where application of APV or TCN-201 reversed the lack of LTD (Fig. 6).

Finally, in support of these results, immunoblots of hippocampal lysate demonstrated a clear upregulation of both GluN2A and GluN2B protein (Fig. 7). Interestingly, a significant increase in the GluN2B/GluN2A ratio was observed in the KO $(p<0.05)$. No significant increase was observed for GluN1 ( $p>$ $0.05)$. In summary, these data are in harmony with enhanced NMDAR signaling function in the KO and are thus consistent with dysregulated NMDAR regulation of mGluR-LTD.

\section{Discussion}

In the present study, we have used both biochemistry and functional assays to investigate the involvement of NMDARs in hippocampal CA1 mGluR-dependent LTD.

We have studied both WT and KO mice from postnatal 15 until almost 7 months old (p200), thus from early juvenile stage to full mature mouse. This corresponds approximately from early childhood through early adulthood in humans, covering a critical time period for brain development. We have used NMDAR antagonists to investigate the involvement of NMDARs in DHPG- induced LTD. Our focus on NMDARs has revealed a clear and strong developmental NMDAR-dependent regulation of mGluR-LTD in the WT mouse, which are dysregulated in the KO mouse, leading to considerable reduction in mGluR-LTD signaling in the KO.

Using a well-known and well-characterized LTD induction protocol (DHPG) (Huber et al., 2001), we confirm that mice lacking FMRP have increased mGluR-LTD (Huber et al., 2002; Michalon et al., 2012); however, this was only observed during a very specific time period at $\sim 1-2$ months of age. At earlier and later time points, mGluR-LTD in the presence of APV was either normal or reduced in the $\mathrm{KO}$.

\section{LTD recorded in the presence of active NMDARs}

Recordings made both in the presence and the absence of APV allowed us to dissect out the underlying NMDAR-mediated mechanism of mGluR-LTD. As seen in Figure 3D, mGluR-LTD in the absence of APV (mGluR-LTD $\left.{ }_{\mathrm{Ctrl}}\right)$, in both WT and KO, peaked at $\sim$ p30 and then decreased throughout the following months. However, after p30, the decline in mGluR-LTD ${ }_{\mathrm{Ctrl}}$ in the $\mathrm{KO}$ accelerated dramatically faster compared with WT. Indeed, at p60, recordings made in the absence of APV had very little or often no LTD presence (Fig. 2D). This LTD block could easily be lifted by including of APV in the recording solution. Thus, in the presence of $\mathrm{APV}$, in the $\mathrm{KO}$, at all time points, the 
A
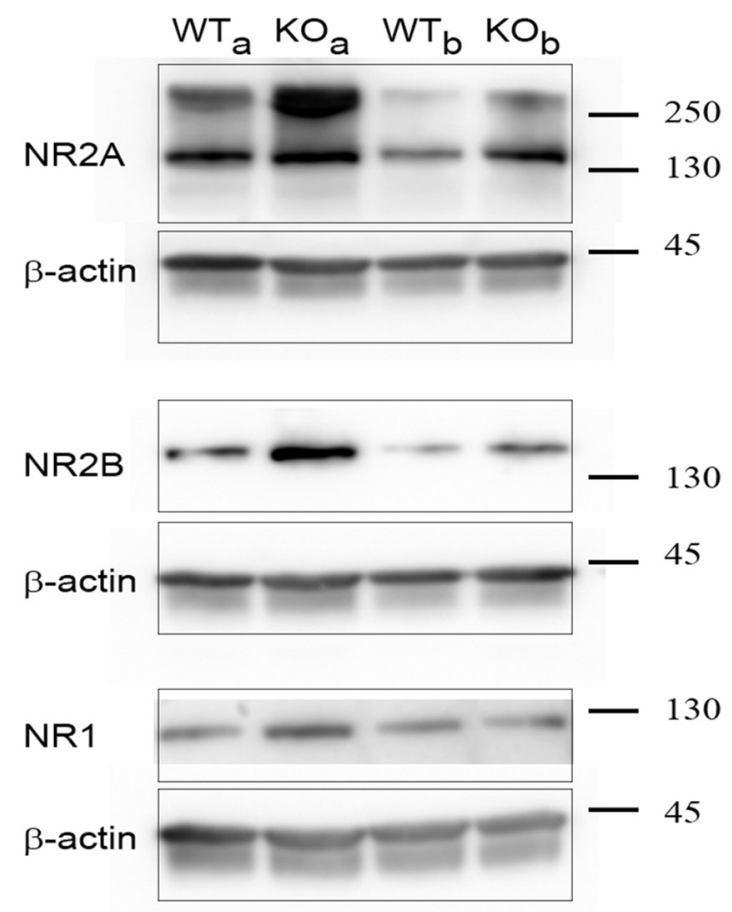

B
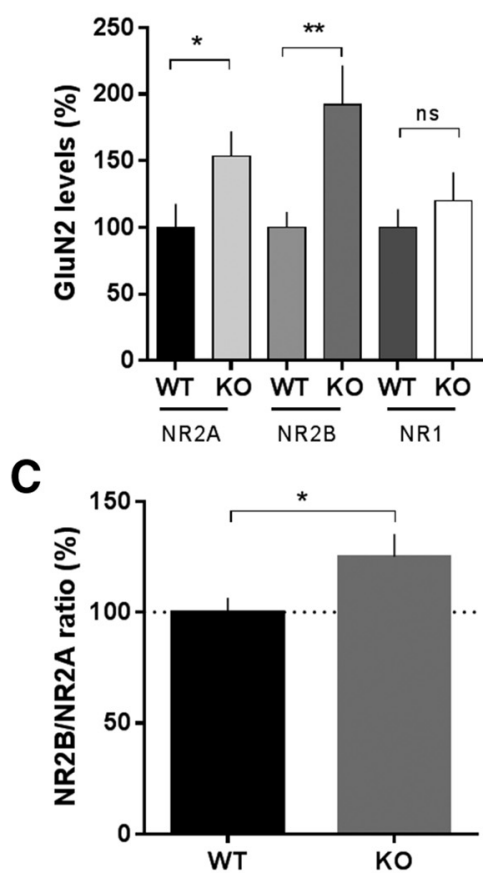

Figure 7. GluN2A and GluN2B are upregulated in K0 hippocampus. Representative immunoblots of GluN2A and GluN2B from whole hippocampus tissue lysate (p60-p80). Proteins were purified in pairs. $A$, Two examples of paired purifications are shown: $\mathrm{WT}_{\mathrm{a}} \& \mathrm{KO}_{\mathrm{a}}$, and $\mathrm{WT}_{\mathrm{b}} \& \mathrm{KO} \mathrm{b}_{\mathrm{b}}$. For GluN2A, a band around twice the size of $\mathrm{GluN2A}(\sim 160 \mathrm{kDa}$ ) was observed that was not included in the analysis. $B$, Protein levels of GluN2A and GluN2B were significantly elevated in K0 compared with WT (GluN2A: $p=0.01 ; G$ luN2B: $p=0.005 ;$ Student's $t$ test). $C, p<0.05$, significant change of the GluN2A/GluN2B ratio in the K0 compared with WT. ${ }^{*} p<0.05,{ }^{* *} p<0.01$, ns, Not significant.

mGluR-LTD + APV were literally identical to mGluR-LTD Ctrl $_{\text {for }}$ WT (Fig. 3D). This strongly suggests that the APV component in the KO is highly manipulative and, furthermore, it is the APVsensitive component in the $\mathrm{KO}$ that is changing rather than the mGluR component itself.

The residual potential obtained by subtracting mGluR-LTD + APV

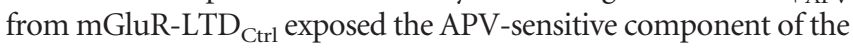
recordings. Interestingly, at $\sim$ p30-p60, the $\triangle \mathrm{APV}$ was significantly different between $\mathrm{KO}$ and WT (Fig. $3 E$ ). Thus, $\triangle \mathrm{APV}$ was much more pronounced in $\mathrm{KO}$ than in WT. This could mean that at or $\sim$ p30, an important NMDAR-mediated signaling is needed for proper brain development, and this signal is lacking or strongly altered in the $\mathrm{KO}$.

\section{Inhibition of GluN2B suppresses LTD}

The two main types of hippocampal NMDARs are GluN2Acontaining and GluN2B-containing receptors, respectively, and although still debated (Bartlett et al., 2007; Morishita et al., 2007; Xu et al., 2009), both subunits have been suggested to play distinct roles in long-term synaptic plasticity (Liu et al., 2004; Massey et al., 2004). Here, at first, blocking GluN2B-containing NMDARs with subunit-specific antagonists in WT resembled the observations from the KO where not blocking NMDARs led to suppressed mGluR-LTD, suggesting that both scenarios are a product of the same mechanism (Fig. 4). This suggests that the GluN2B-signaling pathway is hyperactive in the KO. Thus, this argues that, when the GluN2B to GluN2A ratio increases, this prompt failure in NMDAR regulation of mGluR-LTD (Fig. 4B). Interestingly, in WT, when inhibiting both GluN2A and GluN2B, similarly to the APV (and MK-801) treatment, LTD was completely rescued, implying that GluN2A and GluN2B counteract each other's action. This supports that a delicate balance between GluN2A and GluN2B exists and that both subunits are involved and required in proper mGluR-LTD. This was also observed in the KO thus, blocking both GluN2A and GluN2B (by APV) or GluN2B lead to rescue of LTD (Fig. 4B). Furthermore, in Western blots, we did find an increased GluN2B to GluN2A ratio (Fig. 7). Combined, these experiments suggest that some sort of direct or indirect crosstalk between the NMDAR channel complexes is required and needed for proper NMDAR signaling. Interestingly, using different LFS electric stimulation protocols that introduce a more synaptic-specific form of LTD, we found that, under conditions where the WT exhibit no NMDAR-dependent LTD, LTD in the KO was still strongly NMDAR-dependent (Fig. 5). Indeed, just as when using the DHPG protocol, blockage of NMDARs rescued the LTD in the $\mathrm{KO}$ using either of the two LFS protocols (Figs. 5, 6; Table 2), supporting the hypothesis that NMDARs in the $\mathrm{KO}$ are hyperactive. Although we report an imbalance between diheteromeric GluN2A and GluN2B NMDARs, the existing of triheteromeric NMDARs makes it possible that a more complex signaling pathway could be involved (Paoletti et al., 2013). Overall, this puts the NMDAR in a pivotal role in regulating the level of mGluR-LTD activity.

FMRP is mostly known as a repressor of specific mRNA translation and protein synthesis (Zalfa et al., 2006; Penagarikano et al., 2007) and can thereby potential influence many levels of neuronal excitability by direct or indirect regulating proteins that are involved in cellular excitability (Gatto and Broadie, 2010; Contractor et al., 2015). Thus, our data support a model where NMDARs are dysregulated and no longer regulate mGluR-LTD properly that possibly could lead to neuronal hyperexcitability. In agreement with Schütt et al. (2009), we confirmed a clear 
upregulating of both GluN2A and GluN2B proteins in the KO (Fig. 7).

Interestingly, NMDARs have been reported to stimulate mGluRs, and vice versa (Aniksztejn et al., 1992; Harvey and Collingridge, 1993; Challiss et al., 1994; Lüthi et al., 1994; Fitzjohn et al., 1996; Gereau and Heinemann, 1998; Alagarsamy et al., 1999; Collett and Collingridge, 2004). This feedback loop between mGluR and NMDARs may be important in regulating both NMDAR-dependent and mGluR-dependent forms of synaptic plasticity and could contribute to pathological responses induced by NMDA receptor activation. Our data suggest a critical time window for NMDAR regulation just $\sim 1-2$ months of age. This might be part of the well-known early developmental shift from primarily GluN2B-containing NMDARs to GluN2A-containing NMDARs driven by activity and sensory experience (Paoletti et al., 2013). Such shift in the hippocampus requires activation of both NMDARs and mGluR5 (Matta et al., 2011), and perhaps this signaling is disrupted in the $\mathrm{KO}$ leading to a continuous high activity of GluN2B-containing NMDARs. Thus, hyperstimulation of either NMDAR-mediated or mGluR-mediated signaling during early development could have severe implications on proper brain development and may contribute to FXS disease symptoms and severity.

Our data suggest that the underlying cause of the otherwise well-known enhanced mGluR-LTD in the KO is likely caused by a dysregulated NMDAR signaling. Thus, here, blockage of GluN2B-containing NMDARs restored mGluR-LTD completely in the KO. Hence, in conclusion, our data strongly argue that there could be a great untapped potential in NMDAR-mediated manipulation of mGluR function in the $\mathrm{KO}$ as a therapeutic target in the FXS research.

\section{References}

Alagarsamy S, Marino MJ, Rouse ST, Gereau RW 4th, Heinemann SF, Conn PJ (1999) Activation of NMDA receptors reverses desensitization of mGluR5 in native and recombinant systems. Nat Neurosci 2:234-240 CrossRef Medline

Aniksztejn L, Otani S, Ben-Ari Y (1992) Quisqualate metabotropic receptors modulate NMDA currents and facilitate induction of long-term potentiation through protein kinase C. Eur J Neurosci 4:500-505. CrossRef Medline

Bagni C, Oostra BA (2013) Fragile X syndrome: from protein function to therapy. Am J Med Genet A 161:2809-2821. CrossRef Medline

Bartlett TE, Bannister NJ, Collett VJ, Dargan SL, Massey PV, Bortolotto ZA, Fitzjohn SM, Bashir ZI, Collingridge GL, Lodge D (2007) Differential roles of NR2A and NR2B-containing NMDA receptors in LTP and LTD in the CA1 region of two-week old rat hippocampus. Neuropharmacology 52:60-70. CrossRef Medline

Bear MF, Huber KM, Warren ST (2004) The mGluR theory of fragile X mental retardation. Trends Neurosci 27:370-377. CrossRef Medline

Bolshakov VY, Siegelbaum SA (1994) Postsynaptic induction and presynaptic expression of hippocampal long-term depression. Science 264: 1148-1152. CrossRef Medline

Challiss RA, Mistry R, Gray DW, Nahorski SR (1994) Modulatory effects of NMDA on phosphoinositide responses evoked by the metabotropic glutamate receptor agonist 1S,3R-ACPD in neonatal rat cerebral cortex. Br J Pharmacol 112:231-239. CrossRef Medline

Collett VJ, Collingridge GL (2004) Interactions between NMDA receptors and mGlu5 receptors expressed in HEK293 cells. Br J Pharmacol 142:9911001. CrossRef Medline

Contractor A, Klyachko VA, Portera-Cailliau C (2015) Altered neuronal and circuit excitability in fragile $\mathrm{X}$ syndrome. Neuron 87:699-715. CrossRef Medline

Darnell JC, Klann E (2013) The translation of translational control by FMRP: therapeutic targets for FXS. Nat Neurosci 16:1530-1536. CrossRef Medline

Dudek SM, Bear MF (1992) Homosynaptic long-term depression in area
CAl of hippocampus and effects of $N$-methyl-D-aspartate receptor blockade. Proc Natl Acad Sci U S A 89:4363-4367. CrossRef Medline

Edbauer D, Neilson JR, Foster KA, Wang CF, Seeburg DP, Batterton MN, Tada T, Dolan BM, Sharp PA, Sheng M (2010) Regulation of synaptic structure and function by FMRP-associated microRNAs miR-125b and miR-132. Neuron 65:373-384. CrossRef Medline

Fitzjohn SM, Irving AJ, Palmer MJ, Harvey J, Lodge D, Collingridge GL (1996) Activation of group I mGluRs potentiates NMDA responses in rat hippocampal slices. Neurosci Lett 203:211-213. CrossRef Medline

Gatto CL, Broadie K (2010) Genetic controls balancing excitatory and inhibitory synaptogenesis in neurodevelopmental disorder models. Front Synaptic Neurosci 2:1-19. CrossRef Medline

Gereau RW 4th, Heinemann SF (1998) Role of protein kinase C phosphorylation in rapid desensitization of metabotropic glutamate receptor 5 . Neuron 20:143-151. CrossRef Medline

Harvey J, Collingridge GL (1993) Signal transduction pathways involved in the acute potentiation of NMDA responses by $1 \mathrm{~S}, 3 \mathrm{R}-\mathrm{ACPD}$ in rat hippocampal slices. Br J Pharmacol 109:1085-1090. CrossRef Medline

Hu H, Qin Y, Bochorishvili G, Zhu Y, van Aelst L, Zhu JJ (2008) Ras signaling mechanisms underlying impaired GluR1-dependent plasticity associated with fragile X syndrome. J Neurosci 28:7847-7862. CrossRef Medline

Huber KM, Roder JC, Bear MF (2001) Chemical induction of mGluR5- and protein synthesis-dependent long-term depression in hippocampal area CA1 chemical induction of mGluR5- and protein synthesis-dependent long-term depression in hippocampal area CA1. J Neurophysiol 86:321325. Medline

Huber KM, Gallagher SM, Warren ST, Bear MF (2002) Altered synaptic plasticity in a mouse model of fragile X mental retardation. Proc Natl Acad Sci U S A 99:7746-7750. CrossRef Medline

Lim CS, Hoang ET, Viar KE, Stornetta RL, Scott MM, Zhu JJ (2014) Pharmacological rescue of Ras signaling, GluA1-dependent synaptic plasticity, and learning deficits in a fragile X model. Genes Dev 28:273-289. CrossRef Medline

Liu L, Wong TP, Pozza MF, Lingenhoehl K, Wang Y, Sheng M, Auberson YP, Wang YT (2004) Role of NMDA receptor subtypes in governing the direction of hippocampal synaptic plasticity. Science 304:1021-1024. CrossRef Medline

Lüthi A, Gähwiler BH, Gerber U (1994) Potentiation of a metabotropic glutamatergic response following NMDA receptor activation in rat hippocampus. Pflugers Arch 427:197-202. CrossRef Medline

Martin HG, Lassalle O, Brown JT, Manzoni OJ (2016) Age-dependent longterm potentiation deficits in the prefrontal cortex of the Fmrl knockout mouse model of fragile X syndrome. Cereb Cortex 26:2084-2092. CrossRef Medline

Massey PV, Johnson BE, Moult PR, Auberson YP, Brown MW, Molnar E, Collingridge GL, Bashir ZI (2004) Differential roles of NR2A and NR2B-containing NMDA receptors in cortical long-term potentiation and long-term depression. J Neurosci 24:7821-7828. CrossRef Medline

Matta JA, Ashby MC, Sanz-Clemente A, Roche KW, Isaac JT (2011) mGluR5 and NMDA receptors drive the experience- and activitydependent NMDA receptor NR2B to NR2A subunit switch. Neuron 70: 339-351. CrossRef Medline

Meredith RM, Holmgren CD, Weidum M, Burnashev N, Mansvelder HD (2007) Increased threshold for spike-timing-dependent plasticity is caused by unreliable calcium signaling in mice lacking fragile $\mathrm{X}$ gene Fmr1. Neuron 54:627-638. CrossRef Medline

Michalon A, Sidorov M, Ballard TM, Ozmen L, Spooren W, Wettstein JG, Jaeschke G, Bear MF, Lindemann L (2012) Chronic pharmacological mGlu5 inhibition corrects fragile X in adult mice. Neuron 74:49-56. CrossRef Medline

Michalon A, Bruns A, Risterucci C, Honer M, Ballard TM, Ozmen L, Jaeschke G, Wettstein JG, von Kienlin M, Künnecke B, Lindemann L (2014) Chronic metabotropic glutamate receptor 5 inhibition corrects local alterations of brain activity and improves cognitive performance in fragile $\mathrm{X}$ mice. Biol Psychiatry 75:189-197. Medline

Morishita W, Lu W, Smith GB, Nicoll RA, Bear MF, Malenka RC (2007) Activation of NR2B-containing NMDA receptors is not required for NMDA receptor-dependent long-term depression. Neuropharmacology 52:71-76. CrossRef Medline

Mulkey RM, Malenka RC (1992) Mechanisms underlying induction of homosynaptic long-term depression in area CA1 of the hippocampus. Neuron 9:967-975. CrossRef Medline 
Oliet SH, Malenka RC, Nicoll RA (1997) Two distinct forms of long-term depression coexist in CA1 hippocampal pyramidal cells. Neuron 18: 969-982. CrossRef Medline

Paoletti P, Bellone C, Zhou Q (2013) NMDA receptor subunit diversity: impact on receptor properties, synaptic plasticity and disease. Nat Rev Neurosci 14:383-400. CrossRef Medline

Penagarikano O, Mulle JG, Warren ST (2007) The pathophysiology of fragile X syndrome. Annu Rev Genomics Hum Genet 8:109-129. CrossRef Medline

Pimentel MM (1999) Fragile X syndrome (review). Int J Mol Med 3:639645. Medline

Schütt J, Falley K, Richter D, Kreienkamp HJ, Kindler S (2009) Fragile X mental retardation protein regulates the levels of scaffold proteins and glutamate receptors in postsynaptic densities. J Biol Chem 284:2547925487. CrossRef Medline

Shang Y, Wang H, Mercaldo V, Li X, Chen T, Zhuo M (2009) Fragile X mental retardation protein is required for chemically-induced long-term potentiation of the hippocampus in adult mice. J Neurochem 111: 635-646. CrossRef Medline

Wyllie DJ, Livesey MR, Hardingham GE (2013) Influence of GluN2 subunit identity on NMDA receptor function. Neuropharmacology 74:4-17. CrossRef Medline

Xu Z, Chen RQ, Gu QH, Yan JZ, Wang SH, Liu SY, Lu W (2009) Metaplastic regulation of long-term potentiation/long-term depression threshold by activity-dependent changes of NR2A/NR2B ratio. J Neurosci 29:87648773. CrossRef Medline

Zalfa F, Achsel T, Bagni C (2006) mRNPs, polysomes or granules: FMRP in neuronal protein synthesis. Curr Opin Neurobiol 16:265-269. CrossRef Medline

Zhao MG, Toyoda H, Ko SW, Ding HK, Wu LJ, Zhuo M (2005) Deficits in trace fear memory and long-term potentiation in a mouse model for fragile X syndrome. J Neurosci 25:7385-7392. CrossRef Medline 